https://doi.org/10.26754/ojs_aem/aem.2018293616

Recibido: 20/07/2019

Aragón en la Edad Media

Aceptado: 14/08/2019

29 (2018) 139-164

e-ISSN: $2387-1377$

ISSN: 0213-2486

\title{
LA CONQUISTA CRISTIANA \\ DE LOS CASTILLOS DE CASTIELFABIB Y ADEMUZ Y SU INCLUSIÓN EN EL REINO DE VALENCIA (1210-1261)
}

\author{
THE CHRISTIAN CONQUEST \\ OF THE CASTLES OF CASTIELFABIB AND ADEMUZ, \\ AND THEIR INCLUSION IN THE KINGDOM OF VALENCIA (1210-1261)
}

\author{
Alberto-Jesús MARTíNEZ BEDMAR \\ Universitat de Barcelona
}

Resumen: El presente artículo estudia la conquista cristiana de los castillos de Castielfabib y Ademuz en 1210 por Pedro el Católico, suceso mal tratado y marginado en las historiografías valenciana y aragonesa. Este episodio se estudia a través de la búsqueda de antecedentes de esta campaña militar, así como de las consecuencias que tuvo. Por otro lado, se analiza el encaje territorial que tuvieron las villas de Castielfabib y Ademuz desde la creación del reino cristiano de Valencia en 1240 con la promulgación del Costum por Jaime el Conquistador, hasta la redacción de los fueros romanceados en 1261, donde se incorpora explícitamente estas villas en el reino de Valencia.

Palabras clave: Castielfabib, Ademuz, Pedro II el Católico, Jaime I el Conquistador, Reino de Valencia, siglo XIII.
Abstract: This paper studies the Christian conquest of the castles of Castielfabib and Ademuz in the year 1210 by the king Peter the Catholic, a badly treated and marginalized event in the Valencian and Aragonese historiographies. This episode is analysed through the search of the background of this military campaign, as well as the consequences it had. On the other hand, it is studied the territorial fir that had the villages of Castielfabib and Ademuz since the creation of the Christian kingdom of Valencia in 1240 with the enactment of the Costum, by James the Conqueror, until the drafting of the Catalan Furs in 1261, where explicitly incorporates these villages in the kingdom of Valencia.

Key words: Castielfabib, Ademuz, Peter II the Catholic, James I the Conqueror, Kingdom of Valencia, $13^{\text {th }}$ Century. 


\section{Introducción ${ }^{1}$}

El estudio de la historia de las villas y castillos de Castielfabib y Ademuz durante el siglo XIII ha sido escaso, limitándose su aparición a referencias breves y poco concisas que, en la mayoría de los casos, transmiten la misma información sin valoración previa, pudiendo caer los autores en problemas de transmisión. El territorio comprendido por las históricas villas de Castielfabib y Ademuz tiene una ubicación separada del resto de tierras valencianas - se hallan en la cabecera del Turia, en el primer tramo de paso del río en territorio valenciano - y quizá por ello acostumbra a caer en el olvido de las investigaciones sobre el reino de Valencia.

En estas tierras se distingue el corredor fluvial del Turia, que no se debe confundir con el cauce principal del río. Por motivos de asentamiento defensivo o poblacional, grandes fortalezas como la de Castielfabib y la de Alpuente se encuentran ubicadas, respectivamente, sobre un afluente del Turia -el río Ebrón - y en un barranco - el denominado barranco del Reguero- (Vázquez-Esparza, 2015: 462). A esta localización geográfica se suma el hecho de la temprana conquista cristiana de estos castillos, que tuvo lugar más de veinte años antes del inicio por Jaime el Conquistador de las campañas de conquista del reino de Valencia, y veintiocho años antes de que se conquistara la ciudad de Valencia. Su incorporación a la corona aragonesa fue realizada por el padre del Conquistador, Pedro el Católico, siendo esta conquista en la campaña del verano de 1210 su gesta militar contra los musulmanes más exitosa.

Como se ha indicado, el principal problema que se encuentra en el conocimiento de la historia de la conquista de los castillos de Castielfabib y Ademuz es su inclusión difuminada en estudios generalistas, a pesar de ser una gesta bastante bien documentada. El siguiente obstáculo se halla en los trabajos en torno al origen del reino cristiano de Valencia; la cuestión de la inclusión de estos castillos en los límites regnícolas, debido a un período de dudas y ambigüedades que duró más de una veintena de años, apenas ha sido estudiada en el marco de investigaciones más amplias.

Por todo ello, este estudio tiene el interés y motivación de tratar la conquista cristiana de los castillos cristianos de la cabecera del Turia valenciano, es

1 Abreviaturas utilizadas: ACA=Archivo de la Corona de Aragón; AGN=Archivo General de Navarra; AHN=Archivo Histórico Nacional; AHT=Archivo Histórico Provincial de Teruel; ARV=Archivo del Reino de Valencia; BNE=Biblioteca Nacional de España. 
decir, los de Castielfabib y Ademuz, desde los más remotos antecedentes de esta campaña, hasta su realización, siguiendo a través de las fuentes documentales su paso a manos cristianas hasta la conquista de la ciudad de Valencia y la cuestión de su incorporación definitiva al nuevo reino cristiano de Valencia, confirmada expresa y explícitamente por el rey más de tres décadas después de su conquista.

Para llevar a cabo esta investigación se han utilizado principalmente fuentes documentales primarias, tanto publicadas como inéditas, además de fuentes secundarias que contextualizan el tema y que de manera específica aluden, en mayor o menor medida, a las villas de Castielfabib y Ademuz durante el siglo XIII.

En los apartados siguientes vamos a abordar, en primer lugar, los antecedentes de la conquista cristiana de los castillos de Castielfabib y Ademuz, fijando un marco cronológico entre los años 1142 y 1210, el mismo año de la conquista, comprendiendo los reinados de Ramón Berenguer IV, Alfonso el Trovador y Pedro el Católico. A continuación, nuestra atención se centra en la conquista de Pedro el Católico de 1210, analizando tanto los sucesos previos que condicionaron la campaña militar como sus consecuencias posteriores. El mantenimiento de los castillos y villas de Castielfabib y Ademuz en manos cristianas entre la conquista de estos en 1210 y la capitulación de la ciudad de Valencia en 1238 constituye otro de los aspectos abordados en esta investigación. Y, finalmente, analizamos el proceso de inclusión de las villas de Castielfabib y Ademuz en el nuevo reino cristiano de Valencia, que culminó en 1273.

\section{Los antecedentes de la conquista cristiana de Castielfabib y Ademuz (1142-1210)}

La importancia de los castillos y poblaciones musulmanas de Castielfabib y Ademuz en el proceso de expansión militar de la Corona aragonesa viene avalada por las fuentes documentales conservadas, las cuales indican la voluntad de los monarcas catalanoaragoneses de conquistar las tierras de la cabecera del Turia valenciano desde mediados del siglo XII hasta que, finalmente, este anhelo fue cumplido por Pedro el Católico a principios del siglo XIII.

Efectivamente, aunque la conquista del posteriormente denominado reino cristiano de Valencia se realizó en el segundo cuarto del siglo XIII, la 
voluntad de tomar esas tierras fue un objetivo para las coronas castellana y aragonesa en sus respectivos proyectos de expansión militar hacia el sur. Gual (1953) señala la intención de la monarquía castellana de dotar una salida mediterránea a sus territorios así como la del rey aragonés Alfonso el Batallador (1104-1134), que pretendió alcanzar esta salida al mar para dirigirse a una nueva campaña cruzada en Tierra Santa mediante la toma de algunas plazas y el ataque y sometimiento a tributo de otras. Años más tarde, los cambios políticos en al-Andalus favorecieron que el conde catalán Ramón Berenguer IV quisiera reducir los reductos musulmanes en los territorios al norte del Ebro, consiguiendo también el reconocimiento, en 1151 con el tratado de Tudillén, por parte de Castilla de un área de expansión aragonesa comprendida entre la cordillera Ibérica y las estribaciones de la Penibética (Gual, 1953: 170-172).

El propio Ramón Berenguer IV, como príncipe de Aragón, al confirmar el fuero de la villa de Daroca en noviembre de 1142, estableció unos límites meridionales del término foral darocense que comprendían no sólo Teruel, sino también «[...] Castill Sauib, a Demuz, a Serreilla, ad Alpuent, a la Cirab, a Tor Alba, a Montan, a Linares [...]» (Agudo, 1992: 52; Gual, 1953: 188; Guinot, 1995, 15: Zurita, 1967: 202). Pero estos bordes no se correspondían con un dominio efectivo del territorio por ellos comprendido, sino, como señalan Enric Guinot y otros autores, se trató más bien de la delimitación de un área de influencia para la expansión de dicho Concejo, o para el pastoreo o para el saqueo, pero sin que hubiese ni control sobre ese territorio ni un repoblamiento cristiano del mismo (Guinot, 1995: 15).

También en época de Ramón Berenguer IV se produjo la donación a los templarios de la quinta parte de los castillos de Castielfabib, Ademuz, El Cuervo y Serrella, según se deduce de un documento posterior donde se cambia esta quinta parte por el castillo de Ascó, siendo esta permuta renovada también en tiempos de Alfonso el Casto (Gual, 1953: 189). En ambos casos, se desconocen las fechas exactas:

[...] In comutatione, videlicet, et cambium illus quinte partis quam in Deimus et Castello Habib et Corvo et Serella eorumque terminis, Dei gratia per nos noviter a sarracenis ablatis, ex donaciones felices recordacionis avi nostri Raimundi, comitis Barchinone, et confirmationem patris nostri bone memorie Ildefonsi regis $[\ldots]^{2}$ 
En época de Alfonso II el Casto (1162-1196), el 20 de marzo de 1179, se firmó el tratado de Cazola entre las coronas de Castilla y Aragón, que actualizaba los límites establecidos veintiocho años atrás en el tratado de Tudillén (1151), reconociendo los derechos de conquista de Aragón sobre Valencia y su territorio, en concreto, sobre Valencia, Xàtiva y Biar con todas sus pertenencias, y todo el reino de Dénia hasta la villa de Calp, quedando al sur, en el distrito de Murcia, el área de influencia castellana y su derecho de anexionarla (Gual, 1953: 207; Guinot, 1995: 20-22). Los límites que establece este tratado, fijados en los distritos musulmanes de Valencia, Xàtiva y Dénia, como afirma Enric Guinot, fueron los territorios que en 1240 formaron el reino cristiano de Valencia (Guinot, 1995: 22).

A fin de poder comprender el estado de esta región en vísperas de la conquista cristiana de 1210, es necesario realizar una aproximación al territorio de la cabecera del Turia valenciano, allí donde se ubican los castillos de Castielfabib y Ademuz. Por el norte, limitaban con el señorío de Albarracín y con las villas del eje del Turia, conquistadas por Alfonso II el Casto: Teruel, Villel y Libros (Gual, 1953: 207). Por el lado oriental se encuentra la población de Manzanera, incorporada por Pedro el Católico en 1202 y donada a Berenguer d'Entença el 6 de junio de ese mismo año ${ }^{3}$ con la misión de repoblarla y defenderla de los sarracenos (Alvira, 2010a: 459-461). Hacia el sureste se hallaba parte del territorio musulmán de Alpuente, mientras que por el suroeste estaba la villa castellana de Moya - poblada el mismo año 1210 (Guinot, 1995: 19) - en la frontera occidental de la cabecera del Turia controlada por la corona de Castilla. Esta situación dibuja una bolsa de territorio musulmán, prácticamente rodeada de territorio cristiano, en el que el único eje articulador con los restantes territorios musulmanes era el eje fluvial del Turia, estando todos los castillos de la cabecera del Turia valenciano en una posición de culde-sac. (Mapa 1).

Con anterioridad a la conquista cristiana de los castillos de Castielfabib y Ademuz, ya se había expresado la voluntad por parte de los monarcas aragoneses de incorporar dicho territorio, como pone de manifiesto el fuero de Daroca de 1142 y las posteriores donaciones de una quinta parte de estos castillos realizadas por Ramón Berenguer IV y su hijo Alfonso II el Casto a la orden del Temple. 


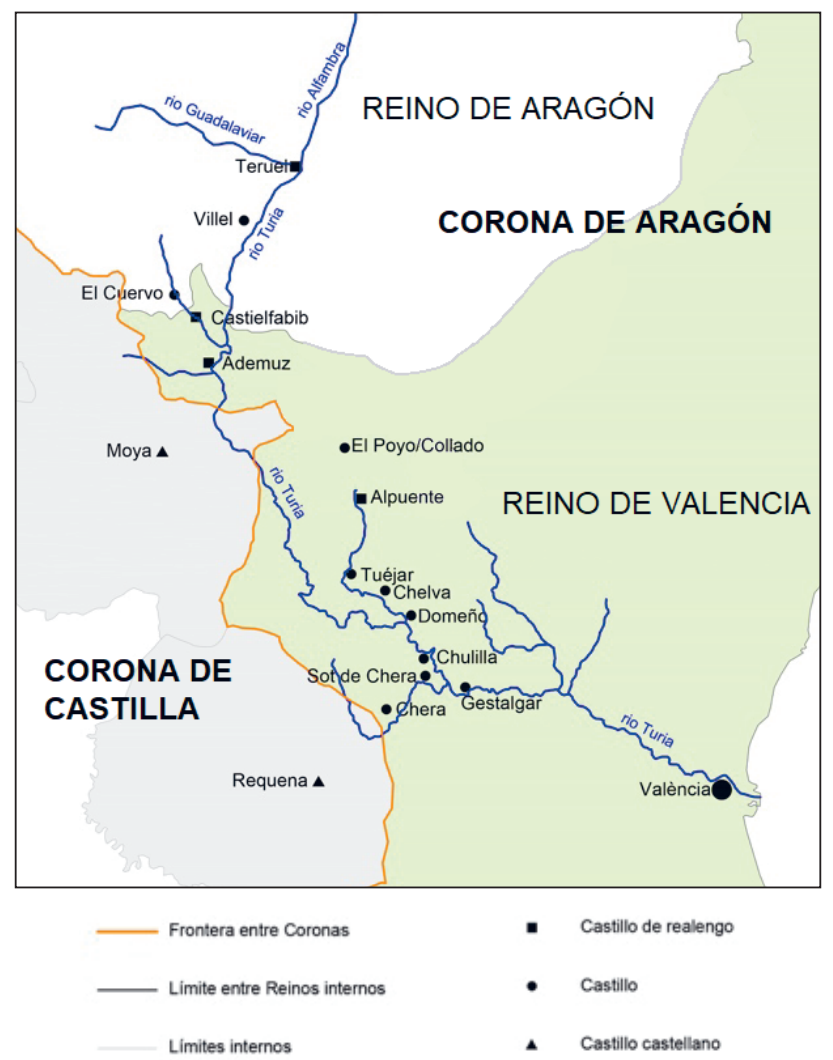

Mapa 1: Castielfabib y Ademuz en la cabecera del Turia valenciano, en los límites del reino cristiano de Valencia entre la promulgación del Costum y 1270. Fuente: Vázquez-Esparza (2015)

\section{La conquista cristiana de los castillos de Castielfabib y Ademuz (1210)}

Como se ha indicado, hacia 1210 la región de la cabecera del Turia valenciano era un territorio musulmán prácticamente acorralado por tierras cristianas, de Castilla por poniente y de Aragón por el área septentrional y occidental. En esa fecha se produjeron dos acontecimientos que repercutieron en la toma de la decisión de emprender una campaña bélica contra los castillos de Castielfabib, Ademuz y otros, llevándose a cabo de este modo la acción militar más fructífera contra los musulmanes del reinado de Pedro II el Católico (1196-1213). 
Según Martín Alvira, desde 1207, el rey aragonés empezó a movilizarse contra los almohades, acelerando los preparativos militares entre los años 1208 y 1209. En febrero de 1210, el papa Inocencio III puso, precisamente, a Pedro II de Aragón como ejemplo para el rey Alfonso VIII de Castilla a través del arzobispo Rodrigo Jiménez de Rada, diciendo que «inflamado por el celo de la fe ortodoxa, ataca la perfidia de los sarracenos». De esta manera trataba de inducir al monarca castellano a imitar la actitud combativa contra el Islam del rey de Aragón (Alvira, 2016: 130).

El primer hecho que repercutió en las acciones del monarca aragonés fue la fundación y población por parte de Alfonso VIII de Castilla de la villa de Moya, situada al sur de los castillos y poblaciones que aquí se estudian, relativamente próxima al cauce del río Turia. Dicha acción, realizada en la primavera de 1210 (Alvira, 2000: 174), venía a consolidar la frontera castellana con el territorio musulmán valenciano a través de la fundación de una nueva localidad y su población de colonos del norte de Castilla, además de conceder fuero a la villa de Moya. Esta acción desagradó a los almohades, los cuales enviaron una protesta al monarca castellano por la población de Moya, señalando que este hecho violaba el acuerdo de paz, pero Alfonso VIII no atendió la reclamación y se preparó para la guerra (González, 1960: 117-118 y 982). Este asunto igualmente pudo disgustar al monarca aragonés, al verse alterados los límites del territorio que se le adjudicó para conquistar en el tratado de Cazola de 1179.

El segundo acontecimiento - que quizás fue consecuencia de la población de la villa de Moya (Alvira, 2000: 174-175) - que sirvió de detonante para la ejecución de la campaña de 1210 de Pedro II el Católico fue un ataque marítimo almohade a la costa catalana, que las fuentes musulmanas describen así:

\footnotetext{
[...] Este año ${ }^{4}$ se dirigió Sayyid Abū-1-'Ulā, el mayor, almirante de las escuadras de los dos países, el país de Barcelona con todas las naves allende el Estrecho y del Andalus, contra la resistencia y oposición de la gente del país [...] y se apoderó de muchos pertrechos y riquezas y fué la más hermosa expedición para los musulmanes y la de mejores resultados y la más completa victoria que obtuvieron los guerreros marinos y la que más fuertemente hirió los corazones de los infieles. (Huici, 1953: 258)
} 
La exposición de los hechos que realiza la crónica musulmana del Anónimo de Madrid parece indicar que este ataque marítimo contra la costa catalana fue la causa principal de la campaña de verano de 1210 de Pedro el Católico,

[...] A raíz de este estrago fue el apoderarse el Barcelonés de los castillos de Valencia en este año que historiamos. (Huici, 1953: 258)

Con estos precedentes, el monarca aragonés estaba dispuesto a emprender la guerra contra los almohades de Valencia, materializándose este ataque en la campaña de julio y agosto de 1210, en la cabecera del Turia valenciano. Según Zurita, Pedro el Católico estaba en Monzón a finales de marzo de 1210 y «allí mandó juntar sus ejércitos para hacer guerra a los moros del reino de Valencia» (Zurita, 1967: 331). Sin embargo, no es hasta mediados de junio de 1210 cuando el rey de Aragón se encuentra en Teruel en disposición de empezar la campaña bélica en la zona (Alvira, 2010b: 1113-1114). Efectivamente, queda documentado que el 21 de junio de 1210 Pedro el Católico confirmaba dos donaciones al monasterio de Poblet durante el asedio de Ademuz: «in obsidione Castri de Deymuz» (Alvira, 2010b: 1115-1119). Unos días más tarde, el primero de julio, el monarca se encontraba en el asedio del castillo de Castielfabib realizando varias concesiones al abad y monasterio de Piedra: «in obsidione Castel Fabib» (Alvira, 2010b: 1123-1124); «in obsidione de Castiel Habib, kalendas iulii» (Ledesma, 1991: doc. 156). ${ }^{5}$

Después de estas menciones, pasa un mes y medio en el que no hemos encontrado referencias documentales a los castillos de este estudio; no obstante, es posible que Pedro el Católico y quienes lo acompañaron en esta campaña continuaron asediando los castillos de la cabecera del Turia valenciano. La siguiente noticia localizada es del 18 de agosto de 1210, cuando, desde Castielfabib, el rey hizo donación de la villa y castillo de El Cuervo - al norte de Castielfabib, en el curso del río Ebrón - , recién conquistados a los musulmanes, a García Romeu, concediéndole todos los derechos e indicando los límites de sus términos (Alvira, 2010b: 1125-1126). ${ }^{6}$

Unos días después, el 24 de agosto de 1210, Pedro el Católico otorgaba un privilegio por el que hacía francos a los hombres de Calatayud. La data

5 La referencia de Alvira procede del AHN, Clero, Piedra, carp. 3.664, n. ${ }^{\circ}$ 7; la referencia de Ledesma se refiere a un traslado notarial del mismo documento conservado en el Archivo Municipal de Teruel fechado en 1375 .

6 AHN, Órdenes Militares, San Juan, Castellanía de Amposta, carp. 583, n. 73. 
del documento dice «in captione Castelli Habib» (Alvira, 2010b: 11271128); es decir, el castillo de Castielfabib ya había sido tomado por el monarca aragonés. No obstante, esta fecha se puede precisar más a través del estudio de las crónicas cristianas del momento. Así, el Chronicon Dertusense II dice que en «Era .M ${ }^{\mathrm{a}} \mathrm{CC}{ }^{\mathrm{a}} \mathrm{CLVIII}$., anno. $\mathrm{M}^{\circ} \mathrm{CCX}{ }^{\mathrm{o}}$., caput est Castrum Habibi a rege VIII $^{\circ}$. die post assumptionem beate Marie» (Iranzo, MartínIglesias, 2015: 272), es decir, que Castielfabib fue tomado el octavo día después del 15 de agosto, festividad de la Asunción de María; debido al cómputo inclusivo medieval, la fecha señalada en la crónica es el 22 de agosto (Iranzo, Martín-Iglesias, 2015: 289).

La toma de Castielfabib y Ademuz tuvo una gran repercusión en las crónicas y anales del momento, quedando referenciada en las Gesta Comitum Barchinonensium: «Nam castrum de Afabib et multis aliis strenuissime occupavit»(Alvira, 2010c: 1658, 1672, 1674; Alvira, 2016: 137); también en el Chronicon Rotense: Anno $\mathrm{M}^{\circ} \mathrm{CC}^{\circ} \mathrm{X}^{\circ}$ Petrus rex, filius eius, anno $\mathrm{XV}^{\circ}$ cepit castellum Daimuz et de Corbo et de Serrellas et de Castellofabiu» (Alvira, 2016: 138); y en las Crónicas de los Jueces de Teruel, donde en el manuscrito A dice «Fue preso Ademuz et Castiel Fabib que lo tenían los moros», y el manuscrito del AHT anota: «En esti año fueron presos Castiel y Ademuz que eran de moros» (López Rajadel 1994: 82-83; Floriano, 1954: 22).

Acerca de la conquista cristiana de los castillos de Castielfabib y Ademuz, una de las crónicas musulmanas traducidas por Ambrosio Huici Miranda aporta interesantes datos para comprender el desarrollo de los acontecimientos:

[...] Este año se apoderó el enemigo barcelonés de los castillos de la región de Valencia y los tomó por asedio y ataque; la mayoría de sus habitantes se le rindió por capitulación y a unos los llevó a su país y otros llegaron a tierra musulmana. (Huici, 1953: 258)

Esto confirma el asedio a las fortalezas de la cabecera del Turia valenciano por parte de los cristianos, tal y como se indica en la documentación aragonesa, pero aporta que los habitantes se rindieron por capitulación, y que unos fueron llevados a tierras cristianas y otros marcharon hacia territorio musulmán. No obstante, la imagen de despoblación que ofrece esta crónica pudo diferir de la realidad que se vivió: hubo habitantes de las poblaciones de Castielfabib y Ademuz que fueron a tierras musulmanas después de la conquista, pero quizá otros se quedaron en esas localidades, según se 
deduce por documentación posterior que menciona población musulmana en estos lugares. ${ }^{7}$

La documentación cristiana sigue mostrando la presencia de Pedro el Católico en Castielfabib. El 26 de agosto donó la iglesia de Castielfabib a la orden del Hospital, con sus diezmos y primicias, y además el lugar de Las Eras, al norte de la población, fijando unos límites para construir una iglesia y unos oratorios, todo ello por la ayuda prestada por los hospitalarios en la toma de Castielfabib. ${ }^{8}$ El mismo día, el rey de Aragón otorgó carta puebla a Castielfabib y, además, entregó a Artaldo de Alagón el Castell de Cabres, cerca de Benifassà, para poblarlo (Alvira, 2010b: 1129-1131; Gual, 1989: 106). Y al día siguiente, 27 de agosto, el notario del rey Ferrer selló un privilegio a los judíos de Zaragoza (Alvira, 2010b: 1131-1132). A finales de mes, el día 30 de agosto, Pedro II se encontraba en Teruel (Alvira, 2010b: 1132-1133). Pero de nuevo volvió hacia Castielfabib el primero de septiembre, para otorgar un fuero y carta puebla a esta villa (Riba, 1915: 239-241).

Acerca del fuero de Castielfabib, existe problemática debido al documento que se conserva en la Biblioteca Nacional de Madrid, ${ }^{9}$ el texto jurídico se compone del fuero de Teruel romanceado en aragonés, pero el topónimo Castiel $^{10}$ aparece raspado o tachado en gran parte de sus apariciones, siendo sustituido por el de Albarracín o Teruel. Otra duda es la datación del documento: «[...] Dada en Castiel las kalendas de setiembre, era $\cdot \mathrm{M} \cdot \mathrm{CC} \cdot \mathrm{XLVII} \cdot[\ldots] »$ (Riba, 1915: 241), correspondiendo este año al 1209, debiéndose tratar de un error de escritura, ya que el Pedro el Católico no se encontraba en ningún otro lugar similar a Castiel en agosto o septiembre del año 1209. ${ }^{11}$ Este documento indica la voluntad real de perdurar el dominio y control del territorio recién incorporado a la corona.

7 ACA, Cancillería, Registros, n. ${ }^{\circ}$ 1960, f. 98v. En Eslava, 2014: 27.

8 AHN, Órdenes Militares, San Juan, Castellanía de Amposta, carp. 583, n. ${ }^{\circ}$ 74. En Alvira, 2010b: 11281129 .

9 BNE, mss. 7.812.

10 Nombre popular de Castielfabib. En el contexto turolense de finales del siglo XII e inicios del XIII ya se observa el uso del nombre Castiel para referirse a Castielfabib, como se puede ver en las Crónicas de los Jueces de Teruel, donde en 1184 se anota que «Don Yuanyes Domingo de Montero fue forcado en el olmo de Sant Lazaro porque quiso vender a los moros de Castiel et de Villel a Teruel» (López Rajadel 1994: 70-71; Floriano, 1954: 20); y también, como antes se ha referenciado, en la noticia de la conquista cristiana de Castielfabib y Ademuz narrada en las diversas versiones de estas crónicas: «En esti año fueron presos Castiel y Ademuz que eran de moros» (López Rajadel, 1994: 82-83; Floriano, 1954: 22).

11 Por esas fechas el monarca se encontraba en Girona (Alvira, 2010b: 1009-1010). 
Tras el éxito de esta gesta militar, se inició un periodo de entusiasmo para el rey. El 6 de septiembre Pedro el Católico concedía a la orden del Hospital y al castellán de Amposta todas las mezquitas de Borriana y su término, dando permiso para edificar iglesias cuando se tomase a los musulmanes (Utrilla, 2017: 48); también, estando en Villafeliche el 1 de septiembre, recompensó a los templarios, con donaciones y privilegios, donde destacan los concedidos sobre Tortosa en reconocimiento a su labor en la campaña de la cabecera del Turia valenciano que originó la toma de los castillos de Castielfabib, Ademuz, El Cuervo y Serrella:

[...] cum laudabili caterva fratrum viriliter nobis assistit in exercitu quem facimus contra sarracenos quando, divina gratia cooperante, cepimus castrum de Deymuz et Castellum Habib et castellum quod dicitur Lo Corvo et castellum quod dicitur Serrella [...] (Alvira, 2010b: 1139-1142; Gual, 1953: 235)

Según el historiador Francisco Diago (1613) - que consultó los archivos reales en el siglo XVII-, para el mantenimiento y prosperidad de las nuevas poblaciones conquistadas, es decir Castielfabib y Ademuz, el rey «[...] otorgó a sus nuevos pobladores, y a los que quisiessen serlo de allí adelante, grandes exempciones, y una muy liberal franqueza de muchas imposiciones y derechos». El mismo autor indica que «He la visto en el Archivo de la Baylia de Valencia, en un libro grande de las otorgadas a pueblos deste Reyno, en la hoja ciento y trynta y cinco», fechada en el 22 de septiembre en Perpiñán (Diago, 1613: 270-271). A pesar de la precisión de la noticia, el monarca aragonés no se encontraba en Perpiñán en esa fecha, sino que estaba entre Villafeliche y Calatayud (Alvira, 2010b: 1142). No obstante esta mala datación, la noticia confirma la voluntad del rey de Aragón de mantener las nuevas conquistas en territorio valenciano.

El 23 de octubre de 1210, el monarca aragonés cambió la quinta parte de los castillos de Castielfabib, Ademuz, El Cuervo y Serrella - que, como se ha dicho anteriormente, habían sido donados por su padre, Alfonso el Casto, y abuelo, Ramón Berenguer IV a los templarios - , por la donación en alodio del castillo y la villa de Ascó, confirmando sus privilegios (Alvira, 2010b: 11471149; Gual, 1953: 235-237).

Después de la exitosa campaña del verano de 1210, se observa en Pedro el Católico la voluntad de emprender la conquista del territorio valenciano, que se inició con las capitulaciones de Castielfabib, Ademuz, El Cuervo y Serrella, 
poblaciones que se encuentran regadas por el Turia o sus afluentes y que forman parte del eje natural que conduce a la ciudad de Valencia (Gual, 1953: 172). El 5 de noviembre de 1211, el monarca aragonés otorgó a los templarios la alquería de Ruzafa, en la huerta de Valencia, con su torre y todos sus términos para cuando se tomase; de forma similar, el 22 de mayo de 1213, Pedro II hizo donación al Temple del castillo y villa de Culla para cuando se ganasen (Gual, 1953: 238).

Acerca del factor humano que participó en la campaña de conquista, se puede realizar una aproximación a través de la documentación expedida en esas fechas, cuyo estudio permite percibir la enorme repercusión que tuvo la acción militar en la corona de Aragón y en los reinos limítrofes. Por el lado eclesiástico, estuvieron presentes los obispos de Tarazona - García Frontíny de Zaragoza - Ramón - (Alvira, 2010d: 2504); además la campaña contó con la presencia de efectivos de las órdenes del Temple,${ }^{12}$ del Hospital,${ }^{13}$ de Calatrava ${ }^{14}$ y de Santiago. ${ }^{15}$ El grupo principal estuvo formado por nobles aragoneses,${ }^{16}$ aunque el número de catalanes que participaron no es nada despreciable.$^{17}$ Finalmente colaboraron algunas milicias urbanas ${ }^{18} \mathrm{y}$ algunos no-

12 Entre los de la orden del Temple estaban Pere de Montagut, maestre; Ponç Marescalc, comendador de Miravet; Guillem de Cadell, comendador de Monzón; Guillem de Montrodon, comendador de Gardeny; Arnaldo Salomón, comendador de Huesca; Pere de Castellnou, preceptor de Ambel y Tarazona (Alvira, 2010d: 2506).

13 Entre los de la orden del Hospital estaban Jimeno de Lavata, gran prior; Jimeno de Lavata, prior de Navarra; Martín de Andués, maestre de Amposta; Frontín, comendador de Casasnovas; Guillermo de Roda, capellán real; Jimeno, capellán del gran prior (Alvira, 2010d: 2506).

14 De la orden de Calatrava estaba Rodrigo Díaz, maestre (Alvira, 2010d: 2506).

15 De la orden de Santiago estaba Fernando González, maestre (Alvira, 2010d: 2506).

16 De aragoneses participaron, entre otros, Adán de Alascún, Arnaldo de Alascún, Artaldo de Alagón, Artaldo de Artosilla, Assalid de Gudal, Ato de Foces, Atorella, Aznar Pardo (mayordomo), Bernardo Panicero (merino de Teruel), Blasco de Alagón, Blasco Maza, Blasco Romeu, Diego Fernández, Fortún Valerio, García Gutiérrez, García Romeu, Gombaldo de Tramaced, Guillermo de Alcalá, Guillermo de Pueyo, Guillermo de Urús, Jimeno Cornel, Juan Garcés, Ladrón, Loferrench de Luna, Marcos de Lizana, Martín de Caneto, Martín Gil de Tramacastiel, Matalón, Miguel de Luesia, Pedro de Alcalá, Pedro de Falces, Pedro de Sesé, Pedro de Villarotar, Pedro Fernández de Azagra (señor de Albarracín), Pedro Gutiérrez (mayordomo), Pedro López de Sábada, Pedro (jurista de Tarazona), Ramón de Pueyo, Rodrigo de Lizana, Sancho de Antillón, Altabella, Arnaldo de Ciscar, Bernardo (sacristán de Tamarite), Domingo (clavero de Fraga), García de Alcalá, Gil de Alcalá, Inés de Alcalá, Jimeno de Coscullano, Marquesa, Sancho Vallés (Alvira, 2010d: 2504-2505).

17 De catalanes participaron Arnau de Timor, Berenguer de Centelles, Berenguer de Cervera, Berenguer de Portella, Bernat de Portella, Galceran de Cartellà, Guillem d'Horta, Guillem d'Ódena, Guillem de Cervera, Guillem de Guardialada, Guillem de Montcada, Guillem de Portella, Guillem Durfort, Guillem Ramon de Montcada, Pere de Creixell, Ponç d'Erill, Ramon de Montcada, Ramon de Montreal (Alvira, 2010d: 2504).

18 Entre las milicias urbanas encontramos las de Calatayud y Teruel (Alvira, 2010d: 2504). 
bles castellanos ${ }^{19}$ y navarros. ${ }^{20} \mathrm{Y}$, como era habitual, se constata la presencia de varios notarios del rey. ${ }^{21}$

En resumen, podemos afirmar que las conquistas de la campaña del verano de 1210 en la cabecera del Turia valenciano se vieron influenciadas e incitadas por la fundación y población de Moya por parte de los castellanos, y por un ataque marítimo a la costa catalana por parte de los almohades. En respuesta, Pedro el Católico decidió hacer la guerra a los musulmanes valencianos en la región de la cabecera del Turia. Después de un asedio de casi dos meses, los castillos capitularon y el rey otorgó fuero a Castielfabib, y franquezas a Ademuz con la intención de perdurar la conquista y consolidarla. Además, la documentación refleja la intención de la Corona de realizar más conquistas en territorio valenciano.

\section{El mantenimiento de Castielfabib y Ademuz en manos cristianas (1210-1238)}

Tras haber analizado la conquista cristiana de los castillos de Castielfabib y Ademuz por parte de Pedro el Católico en el verano de 1210, en este apartado se quiere mostrar la evolución de estas tierras entre el año de su conquista en 1210 y de la conquista de la ciudad de Valencia en 1238, debido a que existe una controversia sobre la permanencia de estas tierras bajo control de la Corona, habiendo autores que defienden que, inmediatamente después de la conquista cristiana, cayeron de nuevo en manos musulmanas. Estas casi tres décadas constituyen un periodo con un importante vacío documental en lo que se refiere a la región de la cabecera del Turia valenciano.

De la década 1210-1220, sólo se conocen dos noticias relativas a los castillos de Castielfabib y Ademuz. La primera es una referencia indirecta castellana de los Anales Toledanos I:

El arzobispo D. Rodrigo de Toledo fizo cruzada, e ayunto entre peones e caballeros mas de ducentas veces mil, é entró á tierra de moros de part de Aragon dia de S. Matheus Evangelista, é priso tres castiellos, Sierra, é

19 De entre los castellanos, participaron Abril García, Alfonso Téllez, Pedro Fernández de Castro, Sancho Núñez (Alvira, 2010d: 2506).

20 De navarros estuvieron, entre otros, Jimeno de Aibar y Pedro Garcés de Aguilar (Alvira, 2010d: 2506).

21 Berenguer de Paredes, Colom, Ferrer, Pere de Blanes, Juan Serrano (Alvira, 2010d: 2504). 
Serresuela, é Mira. Despues cercó á Requena dia de S. Miguel, é lidiaronla con almagenequis, e con algarradas, e con delibra, é derrivaron torres, é azitaras, é non la pudieron prender, é murieron y mas de dos mil christianos, é tornaronse el dia de san Martin, era MCCLVII. (Huici, 1913: 356)

En esta breve nota consta que Rodrigo Jiménez de Rada tomó los castillos de Sierra, Serresuela y Mira, entre finales de septiembre y principios de noviembre, y que entró por territorio aragonés a tierras musulmanas. El primer aspecto de interés se refiere al castillo de Serresuela, uno de los castillos tomados por Pedro el Católico nueve años atrás - el de Serrella-, del cual se desconoce su ubicación pero debió estar entre Ademuz y Alpuente, quizás al sur de la actual Santa Cruz de Moya, pudiendo tratarse del castillo de Sierra. El segundo aspecto destacable es que el ataque a los musulmanes parece que se produjo desde el reino de Aragón, entrando en Santa Cruz de Moya. Y, para ello, resulta necesario que las villas y castillos de la cabecera del Turia valenciano fueran cristianas.

Se conoce otra referencia procedente del testamento de Gil de Lihori, fechado el primero de enero de 1220: Gil de Lihori dejaba a su hijo Furtado de Lihori todas las propiedades que poseía en la villa de Ademuz - que consistían en casas, molinos, hornos, viñas y otros bienes - , y los otros hijos tenidos con su esposa Urraca recibían en herencia las propiedades sitas en la villa de Castielfabib y en la ciudad de Teruel; además, el testador añadía una cláusula mediante la cual, en caso de no tener descendencia, las propiedades de Ademuz deberían pasar a la orden del Temple, y las de Castielfabib a la del Hospital (Mur, 1988: 316-318). Esta muestra de diversas posesiones en estas poblaciones puede ser indicativo de una continuidad aragonesa desde el momento de la conquista y de las franquezas concedidas por Pedro el Católico con la finalidad de atraer población y repoblarlas.

El 27 de diciembre de 1223 el rey Jaime el Conquistador confirmaba el fuero de Castielfabib y las donaciones realizadas por su padre a esta villa: «[...] Don Iagme por la gracia de Dios, rey d'Aragón e compte de Barçelona e señor de Montpeller, qui esto lauda e atorga e confirma» (Riba, 1915: 241242).

En un contexto inminentemente previo al inicio de la conquista por Jaime el Conquistador de los territorios que formaron el reino cristiano de Valencia, se encuentra el vasallaje ante el monarca aragonés de Abū Zayd, antiguo gobernador almohade de Valencia, realizado el 20 de abril de 1229 en Calatayud 
(López, 1995: 35; Zurita, 1967: 431). En estos pactos, el almohade se comprometió a poner en manos cristianas seis castillos - Peníscola, Morella, Culla, Ares, Xèrica y Segorbe - y el monarca aragonés prometía entregarle los castillos de Castielfabib y Ademuz, a condición de darle uno de ellos cuando hubiese tomado, al menos, tres de los seis castillos citados (Barceló, 2000: 23; López, 1995: 36). Es decir, la cesión de Castielfabib y Ademuz a Abū Zayd se aplazaba hasta que el musulmán pudiera cumplir lo acordado (López, 1995: 37). En el año 1231, el antiguo gobernador almohade de Valencia no debió satisfacer el pacto contraído con Jaime el Conquistador, porque éste concedió, a fecha de 26 de febrero, a Sancho el Fuerte de Navarra diversos castillos en prenda por un préstamo concedido por el navarro, entre los que figuran Castielfabib y Ademuz).$^{22}$ Sin embargo, esta situación no se prolongó más de un año, pues en marzo de 1232, el rey aragonés rescató los castillos de Castielfabib y Ademuz del poder de Sancho el Fuerte. ${ }^{23}$

La elección por parte de Abū Zayd de los castillos de la cabecera del Turia valenciano no es casual. Según Pedro López Elum, estas plazas tenían una óptima ubicación para poder emprender acciones militares contra Alpuente, Domeño y Tuéjar, poblaciones ubicadas sobre el curso del Turia o afluentes, y para pretender atacar poblaciones como Chelva o Chulilla (López, 1995: 40).

Otra referencia conocida sobre las villas de este estudio es de origen eclesiástico, fechada el 30 de septiembre de 1232. El arzobispo de Toledo, Rodrigo Jiménez de Rada, llevó a cabo una división de diezmos entre el obispo y el cabildo de Segorbe y en ella se enumeran las plazas recién incorporadas: Tormón, ${ }^{24}$ El Cuervo, Castielfabib, Ademuz, Vallanca ${ }^{25}$ y Santa Cruz de Moya ${ }^{26}$ Desde este año hasta la capitulación de la ciudad de Valencia el 9 de octubre de 1238 , no se ha localizado ninguna otra mención a las poblaciones de Castielfabib y Ademuz.

22 AGN, Comptos, Caja 2, n. ${ }^{\circ}$ 8. En Jimeno, 1998: 313-315.

23 AGN, Comptos, Caja 2, n. ${ }^{\circ}$ 10. En Jimeno, 1998: 323-325.

24 Tormón es una villa y castillo aguas arriba del río Ebrón, al norte de El Cuervo. El desconocimiento de su fecha de conquista podría hacer pensar que también se tomó junto a los demás castillos de la campaña del verano de 1210 .

25 Vallanca era una aldea en el término municipal de Ademuz (actualmente, desde 1695, es una villa) ubicada al oeste de Ademuz; desde los momentos de la conquista debió formar parroquia y dezmería propias.

26 ARV, Pergaminos, n. ${ }^{\circ}$ 99. Santa Cruz de Moya es una villa castellana ubicada aguas abajo del río Turia, al sur de Ademuz. Corresponde al castillo de Sierra tomado en 1219 por el arzobispo Rodrigo Jiménez de Rada, junto al desconocido castillo de Serrella, el cual pudo estar en su entorno. Eslava, 2007: 16; Gual, 1953: 246. 
Podemos concluir que las primeras décadas de permanencia en la cristiandad de los castillos y villas de la cabecera del Turia valenciano constituyen un periodo histórico bastante desconocido debido a las escasas referencias documentales que se han conservado. No obstante, se puede afirmar que el territorio se mantuvo en manos cristianas, a excepción del desconocido castillo de Serrella, el cual, por estar ubicado más al sur, era el más expuesto y en algún momento entre el 1210 y el 1219 se perdió, siendo recuperado en 1219 por el arzobispo de Toledo. El empeño que puso Pedro el Católico en poder lograr una ocupación permanente de este territorio, junto con el testamento de Gil de Lihori del año 1220 y la confirmación de los fueros de Castielfabib por Jaime el Conquistador en 1223, hacen pensar que el territorio de la cabecera del Turia valenciano no se perdió en favor de los musulmanes. Finalmente, Jaime el Conquistador incluyó en los pactos con Abū Zayd la entrega de los castillos de Castielfabib y Ademuz, aunque parece que nunca estuvieron bajo dominio del musulmán. No obstante, estas plazas quedaron un tiempo bajo el control del rey navarro Sancho el Fuerte, a quien el rey aragonés puso en prenda ambos castillos entre los años 1231 y 1232, en garantía de un préstamo.

\section{La inclusión de las villas de Castielfabib y Ademuz en el reino de Valencia (1238-1273)}

Como hemos señalado en los apartados anteriores, los castillos y villas de Castielfabib y Ademuz fueron tomadas por Pedro el Católico en el año 1210 y permanecieron en manos cristianas hasta el momento de la conquista de la ciudad de Valencia en 1238.

Durante estos veintiocho años, ambas poblaciones formaron parte del reino de Aragón, dado que aún no existía ninguna entidad territorial cristiana diferente donde adscribir estas localidades. Pero, como se ha dicho, ambas eran parte del reino musulmán de Valencia, tal y como indican las fuentes almohades: «se apoderó el enemigo barcelonés de los castillos de la región de Valencia» (Huici, 1953: 258). Y también las fuentes cristianas: en 1179, por la firma del tratado de Cazola, se otorga el derecho a conquistar los distritos de Valencia, Xàtiva y Dénia al rey de Aragón; fruto de la unión de estas unidades territoriales islámicas bajo dominio cristiano surgió el reino de Valencia en 1240 (Guinot, 1995: 20-22). 
Con todo esto, sería lógico pensar que las villas de Castielfabib y Ademuz se incluyeron desde este momento inicial en el nuevo reino de Valencia, pero existe una gran duda y controversia.

La primera noticia que se dispone en este periodo es anterior a la fijación de unos límites del reino de Valencia en la primavera de 1240. Se trata de la promesa del rey Jaime el Conquistador - fechada el 13 de febrero de 1240 de entregar al señor de Albarracín, Pedro Fernández de Azagra los castillos y villas de Castielfabib y Ademuz ${ }^{27}$ por un periodo de dos años, a empezar a contar en la fiesta de san Juan Bautista - es decir, el 24 de junio ${ }^{28}$ - , pudiéndose ampliar esta concesión inicial de dos años. ${ }^{29}$ De esta promesa no se ha encontrado información posterior, luego es posible que se llevara a cabo y que el señor de Albarracín ejerciera su poder sobre los castillos y villas de Castielfabib y Ademuz entre el 24 de junio de 1240 y el mismo día de 1242.

En la primavera de 1240, estando Jaime el Conquistador en la ciudad de Valencia, promulgó el Costum, primer texto legislativo propio de la ciudad y reino de Valencia con el que se crea jurídicamente el reino cristiano de Valencia (Guinot, 1995: 31). Esta concesión es el origen del derecho foral valenciano, si bien inicialmente fue un fuero municipal otorgado a la ciudad de Valencia con la voluntad y el propósito de hacerse extensivo a la totalidad del recién creado reino. De esta primera obra legislativa no se conserva ningún original del año 1240, sino copias posteriores que generan el problema de diferenciación de partes originales y añadidos o modificados del primitivo texto concedido por Jaime el Conquistador (Chabás, 1902: 16-18). El carácter municipal del Costum es constatado también en su primera rúbrica -De termino regni et civitatis Valentie-, donde se tratan los límites del término general de la ciudad de Valencia, así como los primitivos bordes del reino, de una manera breve y no muy clara; también muestra el área de expansión de esta ley, dado que aparecen lugares que aún estaban bajo control musulmán, como es el caso de Biar, que se conquistaría posteriormente, en el año 1245 (Chabás, 1902: 29-33). El texto de esta primera rúbrica es el siguiente:

27 «[... castrum et villan de Castiel Fabip et castrum et villam de Adaymuç», ACA, Cancillería, Pergaminos, Jaime I, Serie General, n. ${ }^{\circ} 831$.

28 «...] proximo festo Sancti Johanis Babtiste», ACA, Cancillería, Pergaminos, Jaime I, Serie General, n. ${ }^{\circ} 831$.

29 «[... in duos annos [...] infra dictos annos duos et ultra», ACA, Cancillería, Pergaminos, Jaime I, Serie General, n. ${ }^{\circ} 831$. 


\begin{abstract}
Vocamus et volumus ut regnum Valentie appelletur et sit a rivo de Uldecona usque ad terminum de Biar, et a mari usque ad Alventosam et Almazaneram et ad Sanctam Crucem et ad finem terminorum de Requena, qui dividunt terminum versus Castellam. (Guinot, 1995: 31)
\end{abstract}

Esta delimitación muestra de manera clara las fronteras con el territorio de fuera de la corona de Aragón; sin embargo, en cuanto a los límites internos, la frontera más clara es la septentrional, en el río Ulldecona. La frontera con el reino de Aragón es poco clara. Se sitúa en el río Albentosa, pero dicho curso de agua no cubre la totalidad del borde entre territorio valenciano y aragonés, existiendo una gran parte de límite confuso. El siguiente punto de referencia citado, Santa Cruz de Moya - aldea de Moya-, era una villa cuyo término, según la referencia, habría de extenderse desde el de Requena hasta llegar al de Albarracín. Con tal definición territorial del nuevo reino cristiano no se puede afirmar la inclusión y pertenencia en el nuevo reino de los castillos y villas de Castielfabib y Ademuz.

Veintiún años después, a inicios de abril del año 1261, Jaime el Conquistador juró en las Cortes celebradas ese año en la ciudad de Valencia los fueros romanceados del reino de Valencia, versión que traduce a la lengua catalán la versión anterior latina, es decir, el Costum, y, a diferencia del texto latino, la versión romance muestra unos límites mejor definidos. En este caso, el texto jurídico sí que especifica la pertenencia de los castillos y villas de Castielfabib y Ademuz al reino de Valencia: «[...] e de la serra de Javalambre axí com ix a Castell Phabib e a Ademuç, e aquest dos castels són del regne de València; e de Ademuç, axí com va al terme que parteiz Ares e Santa Creu, [...]» (Guinot, 1995: 31-32).

Al comparar las rúbricas de las versiones de 1240 y 1261, la principal diferencia es la mayor precisión y descripción del territorio en la de 1261, aunque, en esencia, está renovando los mismos límites, aclarando posibles zonas de confusión, siendo la principal que aclara la relativa a la cabecera del Turia valenciano. Para Enric Guinot, las villas de Castielfabib y Ademuz no pasaron a formar parte del reino de Valencia hasta 1261 (Guinot, 1995: 45-46); no obstante, a continuación presentamos un amplio estudio en el que se analiza la documentación relacionada con Castielfabib y Ademuz entre los años 1240 y 1261 y a partir del cual trataremos de valorar esta inclusión.

El primer punto de controversia del Costum de 1240 relacionado con las fronteras se encuentra en el segundo testamento de Jaime el Conquistador, 
datado el primero de enero de 1241 (Soldevila, 1995: 17; Rodrigo, 2009: 74), es decir, casi inmediatamente después que la promulgación del Costum. En este, el rey aragonés, divide sus posesiones territoriales entre su hijo Alfonso, a quien le dejaba todo el reino de Aragón y toda Catalunya, Ribagorza, Pallars, Arán y el dominio del condado de Urgell, mientras que dejaba a su hijo Pedro y a la reina Violante el Rosellón, el Conflent, la Cerdanya y el Vallespir, todo el reino de Valencia, el reino de Mallorca, junto a Menorca y el derecho del infante Pedro de Portugal sobre la isla de Ibiza; y, además, dejaba las villas de Castielfabib y Ademuz, y de Montpellier (Soldevila, 1995: 18-19). ${ }^{30}$ De este testamento se infiere que en 1241 los castillos y villas de Castielfabib y Ademuz no se encontraban incluidos en el reino de Aragón o, de estarlo, no se desea que sean entregados al infante Alfonso; en todo caso, parece que se encontraban más próximos a la órbita valenciana, dado que se expresa el deseo de entregarlos al infante Pedro.

Un segundo punto de controversia se halla en el reparto testamentario de Jaime el Conquistador fechado el 19 de enero de 1248 (Rodrigo 2009: 78). El problema respecto a esta fuente es que, en la actualidad, se encuentra perdida y sólo se conoce la referencia que realiza en sus Anales Jerónimo Zurita, quien pudo consultar el documento en el siglo XVI. En este testamento, el rey aragonés dividió sus posesiones entre cuatro de sus hijos: al primogénito, Alfonso, habido de su matrimonio con Leonor de Castilla, le dejó el reino de Aragón; a Pedro, el primero de los que tuvo con Violante de Hungría, le hizo heredero de Catalunya y del reino de Mallorca; a Jaime le correspondió todo el reino de Valencia; y a Fernando le dejó el Rosellón y la Cerdanya (Zurita, 1967: 551553). Lo más interesante de esta división es que fija límites a cada territorio,

30 «[... Relinquimus Alfonso, primogenito nostro et regine Alionor, totum regnum Aragonum et totam Cataloniam, et Rippacurciam, Palars, Aran et dominum comitatus Urgelli cum omnibus ad predicta loca pertinentubus. [...] Et relinquimus, post obitum consanguinei nostri Nunonis Sancii, Petro, filio nostro et regine Yoles coniugis nostre, Rossilionem, Confluentem, Ceritaniam et Valaspirium cum omnibus eisdem pertinentibus; et relinquimus dicto Petro, filio nostro, totum regnum Valencie a Biar usque ad rivum de Huldecona et a rivo de Alventosa usque in mare et sicut dividit terminus Rachene cum Castella usque in mare; et relinquimus dicto Petro, filio nostro, regnum Maioricarum et Minoricham et totum ius quod P., infants Portegalis dedit nobis in Eviça. Et relinquimus eciam, dicto Petro, filio nostro, Castrum Habib et Adaymuç et dominacionem et villam Montispesulani et Castrum Novum cum tota dominacione eiusdem et castrum de Latis et dominacionem Omelades et castrum de Basaluc et iura que habere debemus in comitatu Melgorii et de Montferran et castrum de Pozola, quod G. de Montpestler tenet in vita sua et jura que habemus in Lupian et in castro de Muntferrer et omnia iura, voces et acciones quas habemus et habere debemus in Carcasses, Termenes, Termenes, Redes, Fonoledes, Amilavo, Amilaves et Galvalda. [...]» (Soldevila, 1995: 18-19). 
dando al reino de Valencia los límites ya conocidos en 1240, a excepción que aclara algún punto, como es el caso de las poblaciones de la cabecera del Turia valenciano:

[...] Por la parte de septentrión eran los límites del reino de Valencia como se continuaban los términos de Castelfabid, Adamuz y Alpuente; y parten término con los de Moya y van a dar en Requena [...] (Zurita, 1967: 552).

La descripción deja claro que estas localidades se consideraban incorporadas al reino de Valencia. Aunque el uso de esta fuente puede ser controvertido al faltar el documento original y no poder contrastarse su contenido, la noticia no hace sino que confirmar lo que el monarca plasmó en su segundo testamento siete años atrás, donde dejaba las villas de Castielfabib y Ademuz vinculadas a la herencia del reino de Valencia.

La siguiente referencia a las poblaciones de la cabecera del Turia valenciano que hemos utilizado es del 4 de junio de 1254, cuando Jaime el Conquistador prometió respetar las caballerías que Álvaro Pérez de Azagra, señor de Albarracín, tenía en diversas poblaciones aragonesas y valencianas, entre las que se encontraban Calatayud, Teruel, Jarque, Castielfabib, Ademuz y Alpuente..$^{31}$ Un mes después, el 6 de julio, el rey aragonés hacía promesa de no quitar estas caballerías al señor de Albarracín, enumerando los lugares: «[...] et de Castel Haviv, et in villa de Daymuz, et in Alpont [...] et in aliis locis in Aragonia $[\ldots] \gg .{ }^{32}$ La mención a Aragón tiene en este documento un sentido amplio que incluye todos los dominios del rey de Aragón, ya que Alpuente no pertenecía al reino de Aragón, pero ello plantea una nueva duda respecto al encaje territorial de Castielfabib y Ademuz.

El 7 de febrero de 1256 Jaime el Conquistador firmó un acuerdo con Álvaro Pérez de Azagra, señor de Albarracín, reconociendo los derechos que el noble poseía sobre diversos lugares entre los que se encuentra Ademuz:

Conocida cosa sia a todos los omnes quomo nos, don Jayme, por la gracia de Deus, rey de Aragón, et de Mayorcas, et de Valencia, comte de Barcelona et de Urgel, et señor de Montpeller, prometemos a vos, Albar Pérez de Açagra que aquella honor que agora a vos de present libramos et la que teniades por nos, ço es, a saber [cita las poblaciones de Calatayud, Jarque, Daroca y Teruel] et Adaymuz con todos sus dreitos, que non vos los

31 ACA, Cancillería, Pergaminos, Jaime I, Serie General, n. ${ }^{\circ} 1369$.

32 ACA, Cancillería, Pergaminos, Jaime I, Serie General, n. ${ }^{\circ} 1377$. 
tolremos ante queramos, que toda esta honor que la tengades de toda vuestra vida $[\ldots]^{33}$

Pero en esta relación no se hace mención especial a la adscripción territorial de la localidad. No obstante, en el mismo documento el monarca aragonés pone bajo protección del señor de Albarracín los castillos de Biar y Almenar: «[...] Ponemos vos en fialdat el castiello de Byar et el castiello de Almenar [...]». ${ }^{34}$

Según Enric Guinot (1995: 46), el 8 de agosto de 1257 Jaime el Conquistador nombró unos oficiales para esclarecer las reclamaciones de daños causados en zonas fronterizas con Castilla, estableciendo uno para Aragón, que controlaría desde Alfaro hasta Requena, y otro para Valencia, que controlaría desde Albentosa hasta el mar y hasta donde limitaba el reino de Valencia con el de Aragón y el de Murcia, refiriendo que ni Castielfabib ni Ademuz pertenecían al reino de Valencia. Pero estos límites no se correspondían a la realidad, dado que el territorio valenciano limitaba al norte de Requena con el término general de Moya, al menos de Sinarcas hasta Arcos de las Salinas, o, como mucho, hasta Castielfabib. El mismo autor también indica que Jaime el Conquistador nombró a Ramón Guillem d'Entença como sobrejuntero de todas las villas y castillos valencianos situados entre el Júcar y el Ulldecona, y hasta los términos de Aras de Alpuente, Albentosa y Chelva. Pero en estos límites se encuentra el mismo problema que en el caso anterior, ya que excluyen territorios como Alpuente o Arcos de las Salinas que pertenecían en ese momento al reino de Valencia. ${ }^{35}$

Con posterioridad a 1261 existe un conflicto - fechado a finales del mes de septiembre de 1270 - entre la villa de Castielfabib y el consejo de la villa castellana de Moya por los límites entre ambos términos y reinos, en el territorio llamado Cireso, que se identifica con la aldea castielera de Arroyo Cerezo, a poniente de la villa. ${ }^{36}$ (Mapa 2)

Finalmente, en un documento dirigido a la villa de Castielfabib datado el 23 de junio de 1273, Jaime el Conquistador confirma la pertenencia de la villa al reino de Valencia y obliga a sus vecinos a que se rijan por los fueros de Valencia y no por los de Aragón ni por los de Teruel

33 ACA, Cancillería, Pergaminos, Jaime I, Serie General, n. ${ }^{\circ} 1440$.

34 ACA, Cancillería, Pergaminos, Jaime I, Serie General, n. ${ }^{\circ} 1440$.

35 Guinot, 1995: 46. La villa de Arcos de las Salinas perteneció al reino de Valencia hasta que Jaime el Conquistador la dona al consejo de Teruel como aldea el 17 de junio de 1269 (Guinot, 1995: 61).

36 ACA, Cancillería, Registros, n. ${ }^{\circ}$ 16, f. 212r. En Guinot, 1995: 63. 


\begin{abstract}
Noverint universi quod nos, Iacobus, etc. per nos et nostros damus et convedimus vobis universis et singulis hominibus de Casteyll Havib, presentibus et futuris et successoribus vestris imperpetuum quod sitis de termino Regni Valentie et quod in omnibus causis civilibus et criminalis ac etiam in peytis, cenis, exercitibus, cavalcatis et eorum redemptionibus, caloniis, iusticiis et omnibus aliis exactionibus regalibus, utamini et teneamini uti secundum forum Valentie et non secundum forum Aragonie vel Turolii, set in omnibus et per omnia exerveamini ad forum Valentie ut superius continetur. Mandantes etc. Data Valentie, novem kalendas iulii anno Domini $\mathrm{M}^{\circ}$ $\mathrm{CC}^{\mathrm{o}}[\mathrm{LXX}]$ tertio. $^{37}$
\end{abstract}

Recapitulando lo expuesto, se puede sostener que Castielfabib y Ademuz ya pertenecían al reino de Valencia con anterioridad a la redacción de los fueros romanceados de 1261, pudiendo haber pertenecido incluso desde la elaboración del Costum en 1240, dado que la documentación de dicha década liga el territorio de la cabecera del Turia valenciano con el reino de Valencia, como queda de manifiesto en los testamentos de Jaime el Conquistador de 1241 y de 1248. No obstante, la documentación muestra importantes lagunas y discordancias que hacen que definir fronteras claras a partir de la información que aporta, sea una tarea compleja y casi imposible y el propio contenido de los documentos resulta contradictorio en ocasiones.

\title{
6. Conclusiones
}

Tras realizar este análisis sobre la conquista e inclusión en el reino de Valencia de las villas de Castielfabib y Ademuz, se pueden extraer las siguientes conclusiones:

La intención de conquistar los castillos de Castielfabib y Ademuz viene, al menos, de tiempos de Ramón Berenguer IV, cuando en 1142 quedaron incluidos dentro del territorio delimitado por el fuero de Daroca y se hizo donación a la orden del Temple una quinta parte de ambos castillos; donación que fue confirmada por su hijo y futuro rey de Aragón, Alfonso el Casto.

La conquista de los castillos de Castielfabib y Ademuz en el verano de 1210 se vio impulsada por la fundación y población de Moya por los castellanos y por un ataque marítimo a la costa catalana por parte de los musulmanes. Estos hechos decidieron a Pedro el Católico a hacer la guerra contra los almo- 


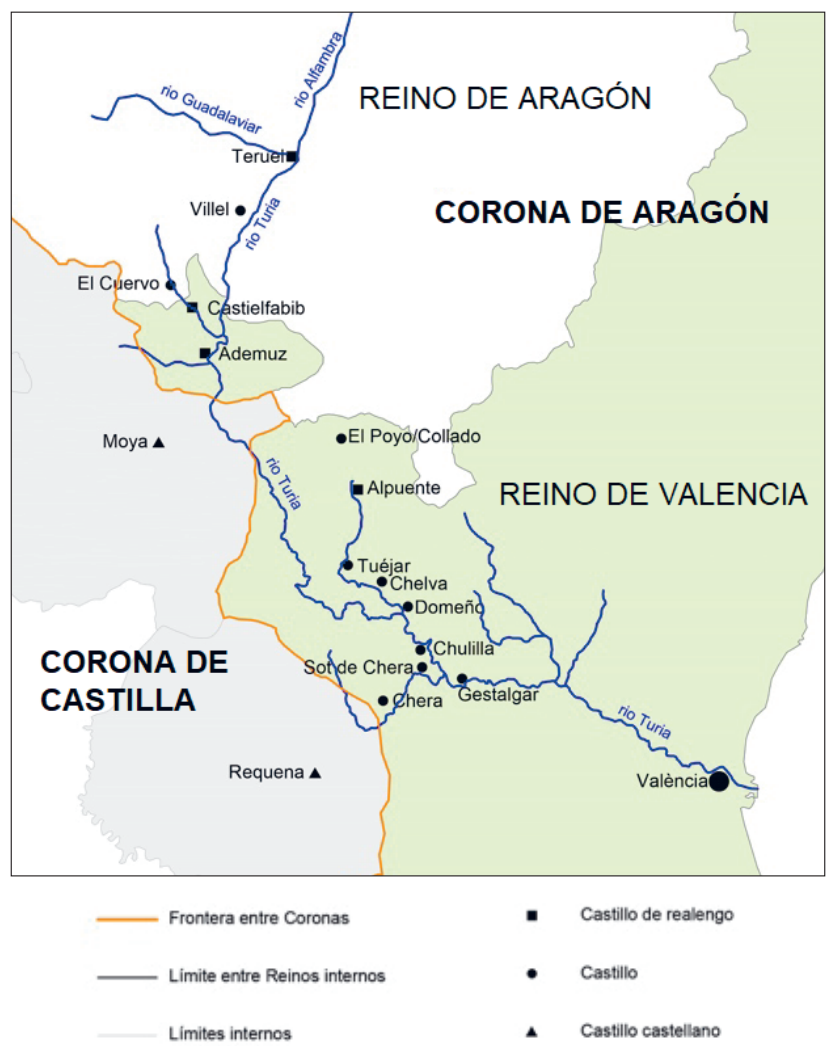

Mapa 2: Castielfabib y Ademuz en la cabecera del Turia valenciano después de 1270. Fuente: Vázquez-Esparza (2015)

hades valencianos. Después de casi dos meses de asedio, los castillos capitularon y el monarca otorgó fuero a Castielfabib y franquezas a Ademuz, quedando patente la intención de perdurar la conquista, consolidarla y, además, la documentación muestra la voluntad regia de realizar más conquistas en territorio valenciano.

Los territorios conquistados por Pedro el Católico en 1210 se mantuvieron en manos cristianas, a excepción de Serrella, que se perdió en fecha desconocida y fue tomada por los castellanos en 1219. De los años comprendidos entre el 1210 y el 1238 se conserva escasa documentación; no obstante, se puede afirmar que este territorio no se perdió sino que se mantuvo bajo dominio cristiano. 
A la luz de las noticias documentales, la incorporación de las villas de Castielfabib y Ademuz al reino de Valencia es un asunto complejo, aunque consideramos que pertenecieron a Valencia con anterioridad a los fueros romanceados de 1261, quizá incluso desde la misma promulgación del Costum en el año 1240 , a tenor de los testamentos de Jaime el Conquistador de 1241 y 1248, en los cuales se relacionan las villas de Castielfabib y Ademuz con el reino de Valencia.

\section{Referencias bibliográficas}

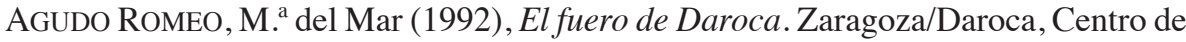
Estudios Darocenses de la Institución Fernando el Católico.

Alvira CABRER, Martín (2000), Guerra e ideología en la España medieval: cultura $y$ actitudes históricas ante el giro de principios del siglo XIII. Batallas de Las Navas de Tolosa (1212) y Muret (1213). Madrid, Universidad Complutense de Madrid, (tesis doctoral).

Alvira CABrer, Martín (2010a), Pedro el Católico, Rey de Aragón y Conde de Barcelona (1196-1213). Documentos, Testimonios y Memoria Histórica, vol. I. Zaragoza, Institución Fernando el Católico.

Alvira CABrer, Martín (2010b), Pedro el Católico, Rey de Aragón y Conde de Barcelona (1196-1213). Documentos, Testimonios y Memoria Histórica, vol. III. Zaragoza, Institución Fernando el Católico.

Alvira CABrer, Martín (2010c), Pedro el Católico, Rey de Aragón y Conde de Barcelona (1196-1213). Documentos, Testimonios y Memoria Histórica, vol. IV. Zaragoza, Institución Fernando el Católico.

Alvira CABrer, Martín (2010d), Pedro el Católico, Rey de Aragón y Conde de Barcelona (1196-1213). Documentos, Testimonios y Memoria Histórica, vol. V. Zaragoza, Institución Fernando el Católico.

AlVIRA CABRER, Martín (2016), Expresiones de la guerra santa en las fuentes del reinado de Pedro el Católico, rey de Aragón y conde de Barcelona (1196-1213), en Carlos de Ayala Martínez; Patrick Henriet; J. Santiago Palacios Ontalva (dirs.), Orígenes y desarrollo de la guerra santa en la Península Ibérica: palabras e imágenes para una legitimación (siglos X-XIV). Madrid, Casa de Velázquez: 127-153.

BARCEló TORRES, Carmen (2000), «El Rincón de Ademuz y su entorno en época árabe», Ababol. Revista del Instituto Cultural y de Estudios del Rincón de Ademuz, 24: 19-27.

CHABÁS Y Llorens, Roque (1902), Génesis del derecho foral de Valencia. Valencia, Imprenta de Francisco Vives Mora.

Diago, Francisco (1613), Anales del Reyno de Valencia, vol. I. Valencia, Casa de Pedro Patricio Mey. 
EslaVA Blasco, Raúl (2007), Ademuz y su patrimonio histórico-artístico. Ademuz, Ayuntamiento de Ademuz.

ESLAVA BLASCO, Raúl (2014), Castielfabib y su patrimonio histórico-artístico. Castielfabib, Ayuntamiento de Castielfabib.

Floriano Cumbreño, Antonio Cristino (1954), «Las efemérides turolenses», Cuadernos de historia Jerónimo Zurita, 2: 7-59.

GONZÁlEZ GonZÁLEZ, Julio (1960): El reino de Castilla en la época de Alfonso VIII, vol. I. Madrid, Consejo Superior de Investigaciones Científicas, Escuela de Estudios Medievales.

Gual Camarena, Miguel (1953), Precedentes de la reconquista valenciana. Valencia, Consejo Superior de Investigaciones Científicas, Instituto Valenciano de Estudios Históricos, Institución Alfonso el Magnánimo.

Gual Camarena, Miguel (1989), Las cartas pueblas del reino de Valencia: contribución al estudio de la repoblación valenciana. Valencia, Generalitat Valenciana.

GUINOT RODRÍGUEZ, Enric (1995), Els límits del Regne. El procés de formación territorial del País Valencià medieval (1238-1500). Valencia, Edicions Alfons el Magnànim.

Huici Miranda, Ambrosio (1913), Las crónicas latinas de la reconquista. Valencia, Hijos de F. Vives Mora.

Huici MiRAnda, Ambrosio (1953), Colección de crónicas árabes de la reconquista. Volumen II. Al-Bayān al-mugrib fi ijtisār ajbār muluk al-Andalus wa al-Magrib por Ibn Idāri al.Marrākušs . Tetuán, Editora Marroquí.

IrANZO Abellán, Salvador; MARTín-IGLesias, José Carlos (2015), «Los Annales Dertusenses anni 1210 (olim Chronicon Dertusense II) (Díaz 1188): edición, traducción, análisis lingüístico y estudio histórico», Evphrosyne. Revista de Filologia Clássica, 43: 265-293.

Jimeno Aranguren, Roldán; Jimeno Jurío, José María (1998), Archivo General de Navarra (1194-1234). San Sebastián, Eusko Ikaskuntza.

Ledesma Rubio, María Luisa (1991), Cartas de población del reino de Aragón en los siglos medievales. Zaragoza, Institución Fernando el Católico.

LÓPEZ ELUM, Pedro (1995), La conquista y repoblación valenciana durante el reinado de Jaime I. Valencia, Federico Domenech.

López Rajadel, Fernando (1994), Crónicas de los jueces e Teruel (1176-1532). Teruel, Instituto de Estudios Turolenses.

Mur i Raurell, Anna (1988), La encomienda de San Marcos. La orden de Santiago en Teruel (1200-1556). Teruel, Instituto de Estudios Turolenses de la Excma. Diputación Provincial de Teruel.

RIBA Y GARCÍA, Carlos (1915), Carta de población de la ciudad de Santa María de Albarracín según el códice romanceado de Castiel existente en la Biblioteca Nacional de Madrid. Estudio preliminar y transcripción. Zaragoza, Tipografía de Pedro Carra. 
Rodrigo Estevan, M. . Luz (2009), «Los testamentos de Jaime I. Repartos territoriales y turbulencias políticas», Cuadernos CEHIMO, 35: 61-90.

SoldeVila i Zubiuru, Ferran (1995), Pere el Gran. Primera part: l'Infant. Barcelona, Institut d'Estudis Catalans.

UTRILla UtRILla, Juan F. (2017), «De la "Extremadura" aragonesa al reino de Valencia: las tierras de frontera entre el mundo cristiano feudal y el Sharq al-Andalus (1170/1240)», en Esteban Sarasa Sánchez (dir.), Bajar al reino. Relaciones sociales, económicas y comerciales entre Aragón y Valencia: siglos XIII-XIV.Zaragoza, Institución Fernando el Católico: 31-61.

VÁZQUEZ-ESPARZA, Álvaro (2015), «La estructura defensiva del río Turia en la cabecera del territorio valenciano», Arché. Publicación del Instituto Universitario de Restauración del Patrimonio de la UPV, 10: 461-470.

ZURITA y CASTRo, Jerónimo (1967), Anales de la Corona de Aragón, edición de Ángel Canellas López, vol. I. Zaragoza, Institución Fernando el Católico. 